\title{
A integração da América Latina na educação bolivariana da Venezuela: concreticidade e formação a partir do sul
}

\author{
Débora Villetti Zuck*
}

Francis Mary Guimarães Nogueira**

\section{Resumo}

O "espectro" da integração latino-americana ronda o continente e nossa inquietação moveu-se pelo desenrolar revelador que adquire na educação bolivariana da Venezuela, de 1999 a 2009. Dessa forma, este artigo propóe-se a identificar e analisar a categoria integração da América Latina expressa nos documentos oficiais e na base legal educacional venezuelana. A integraçáo, concebida como cooperaçáo, solidariedade e complementaridade, tem sido um instrumento importante na luta anti-imperialista, anticapitalista e, num mundo pluripolar, almejado pelo país. Compartilha-se o entendimento de que a educação não tem caráter autônomo nem hegemônico diante das relaçôes sociais em que está "mergulhada”. Logo, expressa a categoria analítica nas orientaçôes filosóficas do currículo, no caráter das Escolas Bolivarianas, nos objetivos e conteúdos do Liceu, na definição de Estado Docente e como uma das finalidades na LOE/2009, daí o interesse em perseguir sua concreticidade, pois orienta a formação do "homem novo" venezuelano e a construção do Socialismo do Século XXI.

Palavras-chave: Integração regional. Venezuela. Política da Educação.

\footnotetext{
${ }^{*}$ Mestre em Educação pela Universidade Estadual do Oeste do Paraná (UNIOESTE). Pedagoga na Universidade Federal da Integração da Integração Latino-Americana (UNILA).

** Doutora em Educação pela Universidade Estadual de Campinas ((UNICAMP). Professora do Curso de Pedagogia e da Pós-Graduação em Educaçăo na UNIOESTE.
} 


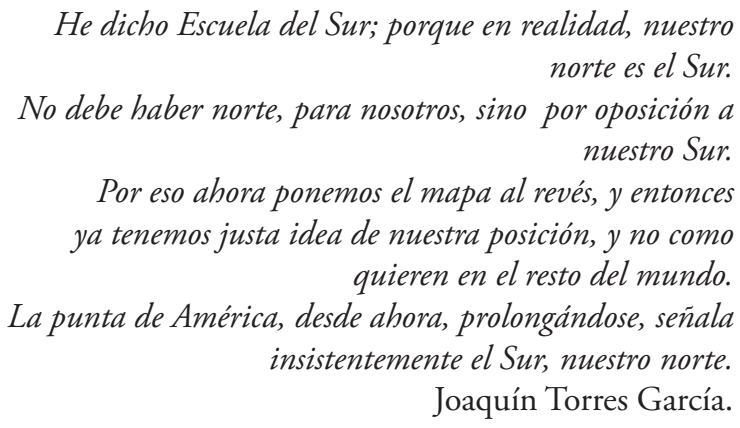

\section{Introdução: uma aproximação necessária com o objeto}

A passagem trazida ao iniciar este trabalho, leva-nos a refletir sobre as nuances e interfaces que caracterizam as relaçōes norte-sul: posiçōes, interposiçōes, sobreposiçóes de países e regióes. Leva-nos, também, a questionarmos: Somos de que latitude? Qual é o nosso "norte"? O que é uma escola do Sul? O universalismo ao avesso, apontado por Joaquín Torres Garcia (1941) sugere inverter posiçōes que não são meramente geográficas, referindo-se ao mapa da América do Sul invertido, e aponta para a necessidade de olhar de outra forma à realidade latinoamericana, que não a eurocêntrica, mas a partir de dentro. Tendo em vista essa necessidade, este estudo ${ }^{1}$ permeia o "espectro" da integraçáo latino-americana que ronda o continente e, particularmente, a inquietaçáo moveu-se pelo desenrolar revelador que esse adquire na educação bolivariana da Venezuela do século XXI. O sentimento de pertencimento à nossa América e a "contaminação" do legado histórico de um projeto integracionista ainda por fazer - citando Martí (apud PIVIDAL, 2009, p. 19): "Lo que Bolívar no hizo, está todavía por hacer en América" - trouxe consigo imerso, nesse turbilhão de conhecimentos, o emaranhado simbólico que o tema desperta. Sabe-se que o pesquisador deve evitar as pré-noçóes no envolvimento com o tema da pesquisa, ao mesmo tempo, porém, a escolha do objeto não é neutra, nem mesmo, desprovida de interesses, e, sim, ligada a escolhas subjetivas, políticas e ideológicas. A aproximação e o envolvimento com um determinado objeto náo dispensa o compromisso com o rigor científico e a busca por se aproximar o máximo possível da realidade concreta. Trata-se de ver com olhos livres ${ }^{2}$ o que "nos molda", que se revela na história e na luta de classes, a partir das contribuiçóes realizadas a partir da e para a América Latina, pois o Sul também existe ${ }^{3}$. 
A América Latina abarca nações diferentes, todas com desenvolvimento capitalista dependente, umas com padrão relativamente importante, outras com processos industriais incipientes; países com concentraçóes urbanas elevadas e com população rural; além de diferenças populacionais, desigualdades de PIB; países com população originária, com idioma e cultura conservada. Cogitar em integração latino-americana requer que se compreenda essa latitude e esse espaço determinado, de fronteiras instáveis, elementos culturais fluidos, étnicos, modos de viver, mescla cultural de povos diferentes, características impensáveis no continente europeu, cuja integração ocorre entre naçôes consolidadas, estáticas e seguras. $\mathrm{O}$ processo integracionista ocorre entre países e abrange distintos âmbitos, como o social, o econômico, o político, o cultural, o educacional.

Entende-se que a concreticidade do real demanda sucessivas aproximaçôes para ser apropriada não se esgota numa pesquisa. Enquanto apreensão de uma minúscula parte da totalidade, o estudo proposto centrouse em identificar e analisar a categoria integração da América Latina na educação bolivariana da venezuelana, no período de 1999 a 2009, enquanto parte constitutiva do entendimento da atual realidade venezuelana, onde está imbricada toda a pequena história da educaçáo bolivariana. Toda porque abrange significativa formulação e implementação de políticas e programas. E pequena em razão do breve tempo histórico de desenvolvimento, mas que, por outro lado, tem suas raízes fincadas no pensamento libertário do processo de independência política do jugo espanhol, no movimento que originou algumas repúblicas, no século XIX, mas que não logrou que se materializasse um projeto latino-americano, a Pátria Grande de Bolívar ou a Nossa América de Martí (CASANOVA, 2009).

Para tanto, fez-se uso da pesquisa documental com base em documentos legais e oficiais venezuelanos, bibliográfica com revisão de literatura de autores que analisam o processo venezuelano e de campo com a observação in loco. Sabe-se que a investigação, produção e difusão de conhecimento científico é um elemento fundamental para apreender a realidade social e transformá-la, o que não dispensa o compromisso do investigador e o rigor teórico-metodológico. Sinaliza-se que este é um momento importante de aproximaçáo desta minúscula parte do real, em que se processam mudanças políticas, econômicas e sociais no referido país. A educação é parte das relações estabelecidas na sociedade e, como tal, expressa o movimento contraditório do real, os embates e projetos em confronto que aí são forjados. 
A problematização procurou contribuir para desmistificar um aspecto da realidade de intervenção política e da prática social não só da educação venezuelana, mas latino-americana. Fundamenta-se numa concepção crítica da realidade, perseguindo condicionantes e determinantes que interferem na dinâmica que move o objeto de estudo, com o qual interagem os agentes políticos, econômicos e sociais para manterem ou alterarem o instituído, num processo de síntese dialética da correlação de forças sociais em cada momento histórico do real.

Na sistematização do estudo, o trabalho está organizado da seguinte forma: inicialmente, abordamos a incidência da categoria integração latino-americana nas Políticas Educacionais venezuelanas que emergem nos governos Chávez, delineando a formação em valores determinados. Nesta seção, foram analisados os documentos educacionais oficiais Escuelas Bolivarianas (VENEZUELA, 2006) e Diseño Curricular del Sistema Educativo Bolivariano (VENEZUELA, 2007a) e a base legal a Ley Orgánica de Educación (VENEZUELA, 2009). Na sequência, perseguimos os vínculos que embasam a incidência da categoria estudada na educação, ou seja, trata-se do aporte que a sustenta no âmbito econômico e social, como parte das relaçóes políticas internas e externas do país. Por fim, estão dispostas algumas consideraçôes provisórias para uma questáo que permanece na realidade latino-americana, com possibilidades e desafios que se descortinam na luta.

\section{A integração latino-americana articulada à formação: uma análise das Políticas Educacionais venezuelanas}

Em 1999, no marco da constituinte educativa, processaram revisóes na Política Educacional venezuelana, proposiçóes para a elaboração da nova Constituição. Essas revisóes avaliaram o impacto e o alcance da reforma curricular de 1997, concluindo que a educação venezuelana estaria fortalecendo o individualismo, a intolerância, o consumismo e a competição, próprios do capitalismo. A visão de educação bolivariana seria delineada nesse processo e contemplada num projeto educativo nacional. Trata-se, conforme Solis (2005), de uma educação que revaloriza e atualiza o ideário político-educacional dos Simones caraquenhos, Rodríguez e Bolívar $^{5}$, retomando a mensagem republicana, democrática, autógena, criativa e integracionista.

No marco dos princípios constitucionais para a educação, aprovada a Carta magna, e do Plano de Desenvolvimento Econômico e Social da Nação 
2001-2007 (PDES), o Estado venezuelano propôs e implementou Políticas Educacionais, planos, programas e projetos ${ }^{6}$ para dar respostas ao novo modelo político e social do país, para assegurar a inclusão, a permanência e a conclusão dos estudos em todos os níveis educativos, "[...] lo cual ha implicado transitar hacia una educación emancipadora y dignificante" (VENEZUELA, 2007a, p. 34). Para alcançar esses propósitos, as estratégias utilizadas foram os projetos-bandeira, desenvolvidos em escolas-piloto. Duas resoluçóes, de setembro de 1999, iniciariam o desenvolvimento dessas estratégias, com caráter experimental durante um período de três anos e em paralelo ao sistema escolar que já existia naquele país, desde a Lei Orgânica de 1980. A Resolução nº 179 (VENEZUELA, 1999a) cria as Escolas Bolivarianas para atender a população estudantil dos níveis de pré-escola, primeira e segunda etapa da educaçáo básica, sendo também utilizadas como centros de formação de adultos (JÁUREGUI, 2006). E a Resoluçấo n. 177 (VENEZUELA, 1999b), referente à Escola Técnica Robinsoniana, com enfoque de educação para o trabalho. Em 2003 elas seriam incorporadas ao novo mapa estratégico da educação bolivariana, que na sua estruturação e implementação, foi chamada nos documentos oficiais de Sistema Educativo Bolivariano - que foi composto dos seguintes níveis: Proyecto Simoncito - Educação Infantil, em tempo integral ${ }^{7}$, maternal de 0-3 anos e pré-escolar de 3-6 anos; Escuela Bolivariana - Educação Básica, educação em tempo integral da criança de 7-12 anos, correspondente ao $1^{\circ}$ a $6^{\circ}$ grau; Liceo Bolivariano - Ensino Médio, diversificado ou profissional, educação em tempo integral a adolescentes e jovens dos 13-18 anos; Educación Técnica Robinsoniana y Zamorana-Ensino Técnico, ensino médio profissional; Universidad Bolivariana de Venezuela - UBV, Ensino Superior; e Sistema Nacional Inclusivo de Misiones ${ }^{8}$ - Robinson (I Alfabetização, II Educaçáo primária e promoção da leitura e III Capacitação de ofícios - para os que não querem avançar a outros níveis), Ribas (Continua a escolaridade e o ensino profissional, destinada aos aspirantes à graduação) e Sucre (Ensino Superior). Esse sistema da educação bolivariana procura corrigir as distorçóes e a exclusão de todos os que estão à margem do sistema educacional na Venezuela.

No interior desse sistema a categoria integração latino-americana está inscrita. Aparece nas bases conceituais filosóficas do projeto Escolas Bolivarianas, denominação que representa uma grande responsabilidade pela conotação histórica que evoca e convoca. A referência ao Libertador, Bolívar, suas ideias e açôes, faz alusão à nacionalidade: destacar o bolivariano remete ao melhor das 
tradições e aos fundadores da nação, reivindica as potencialidades e as fortalezas como país e como povo, abrindo possibilidades para contextualizá-lo e ressignificálo na realidade de hoje (VENEZUELA, 2006). O ideário bolivariano aponta para a função da educação, as luzes, como primordial para a realização humana, pois "[...] un pueblo ignorante es un instrumento ciego de su propia destrucción [...] adoptan como realidades las que son puras ilusiones [...]" (BOLÍVAR, 2009, p. 57). A noção "bolivariana" corresponde à escola que assume a ideia de mudança, de ruptura, de persistência e de reflexão, que reconhece, enquanto nação, sua história e suas referências comuns, que se constroem e reconstroem na ação diária, na capacidade para assumir um projeto conjunto.

[...] el carácter bolivariano de las escuelas nos recuerda que somos latinoamericanos y caribeños, y que como tales, tenemos que ver y comprender hacia el Sur, hacia Centroamérica y las Antillas, porque nuestra suerte es necesariamente compartida y las posibilidades de futuro común están atadas a nuestra capacidad de integración. (VENEZUELA, 2006, p. 14).

Significa o compromisso que deve ser traduzido em sala de aula, convertendo os ideais em realidade. Evoca-se o legado bolivariano de uma história compartilhada e de possibilidade futura também em comum: na capacidade de integração entre os países da região, para recuperar a unidade latino-americana e suas soberanias. A necessidade de formar o estudante latinoamericano com a consciência de unidade é parte da construção de um modelo alternativo de integração latino-americana. Para Manzur (2005, p. 47), "Es necesario introducir, desde la escuela, en la personalidad colectiva del hombre latinoamericano, la idea de la unidad y de los valores y orientaciones comunes de la integración".

Também no ensino médio, que cabe ao Liceu Bolivariano, a alusão à integraçáo latino-americana aparece vinculada aos objetivos gerais e aos conteúdos a serem transmitidos, como nas passagens abaixo:

Bloques económicos, procesos integracionistas (ALBA; MERCOSUR, PETROCARIBE, entre otros). Profundización en el papel de las organizaciones internacionales en el contexto actual. (VENEZUELA, 2007b, p. 268). 
Apropiación y demostración en su modo de actuación de las características de la ciudadanía venezolana a partir de reconocimiento de la diversidad, lo pluricultural, multiétnico y lo protagónico. Proyecto nacional Simón Bolívar y la política internacional. Actualización de la situación geopolítica internacional y nacional y el mundo multipolar. Integración y diálogo (ALBA, MECOSUR, PETROSUR, PETROCARIBE). (VENEZUELA, 2007b, p. 340).

Esses fragmentos indicam que a educação bolivariana, nos diferentes níveis de ensino, estaria concretizando e formando para a integração latino-americana em determinada orientação que, em tese, está ligada ao caráter bolivariano do projeto integracionista, também presente na escola.

As Escolas Bolivarianas são orientadas pelo Diseño Curricular del Sistema Educativo Bolivariano (VENEZUELA, 2007a), enquanto Currículo Nacional Bolivariano que delineia as bases históricas, pedagógicas, filosóficas, sociais, culturais, psicológicas, políticas, metodológicas, científicas e humanistas, a partir das quais se implementa a formação das crianças, jovens e adultos venezuelanos. Recorre a uma pedagogia latino-americana, a práxis integrada, além de Rodríguez e Bolívar, por Miranda ${ }^{9}$, Zamora ${ }^{10}$, Figueroa ${ }^{11}$, Sanjuán ${ }^{12}$, Martí $^{13}$ e Freire ${ }^{14}$.

Sobre os fins e princípios do sistema, o currículo explicita que a instituição educativa deveria promover, entre outros, o desenvolvimento de uma consciência patriótica e republicana consubstanciada com a identidade local, regional e nacional, com visão latino-americana, caribenha e universal, bem como a reconstruçáo histórica, para o fortalecimento da identidade venezuelana (VENEZUELA, 2007a). E o perfil do/a estudante e do/a professor/a que deve ter conhecimento e valorizar a nova geopolítica internacional e as alianças de cooperação e integração da Venezuela com outros países da América Latina, Caribe e o mundo.

A Lei Orgânica de Educação, aprovada em 13 de agosto de 2009 (LOE/2009), é a referência norteadora da educaçáo venezuelana na atualidade e, portanto, central para se pensar a integração latino-americana na educação, pois, enquanto base legal, define a orientação da educação, seus princípios e finalidades. Emerge após um período de quase trinta anos da última legislação educacional oficial, a Lei Orgânica de Educação de 1980. Ao que parece, isso 
não é um problema, pois todo este tempo tem uma positividade: indica que a questão central não é a educação, mas a mudança no conjunto da sociedade, que está movendo a escola e a alteraçẫo na legislaçâo educacional.

Ao dispor sobre os princípios e valores que orientam a educação indicando como o conceito de integração aparece articulado à formação, a Lei estabelece "[...] la formación para la independencia, la libertad y la emancipación, la valoración y defensa de la soberanía, [...] el fortalecimiento de la identidad nacional, la lealtad a la patria e integración latinoamericana y caribeña" (VENEZUELA, 2009, p. 3-4). Por tratar de princípios e valores norteadores da educaçáo, revela sua centralidade na atualidade para pensar o projeto integracionista por meio da educação. Além disso, na lei, a discussão sobre o Estado Docente - que não está na Constituição, mas está na LOE/2009 vincula-se ao conceito de soberania do Estado sobre toda a sociedade e que lhe permite estabelecer mecanismos de integração e difundi-los na escola. O Estado Docente só pode ser pensado na perspectiva de ser soberano.

Há um movimento de transição, em razão da crise do regime político da IV República, representativo e clientelista, para a V República, em desenvolvimento, orientada à criação e ao fortalecimento de uma democracia sustentada na participação e no protagonismo do povo e passa pela anunciação, em 2005, e, posteriormente, pelo debate para a construçấo do Socialismo do Século XXI, mudanças nas formas de propriedade e o incentivo legal e de investimento à participação popular (GIORDANI, 2009; ARAQUE; ROJAS, 2007). O Estado dirige essa transição, rompendo com algumas bases jurídico-políticas das leis do mercado capitalista, induzindo e financiando programas, criando ministérios e instituições para a participação popular, um processo recente que só o movimento histórico concreto da luta de classes determinará seu alcance ou não. A instituição escolar, de forma mediatizada e com muitas contradições, tende a reproduzir essas relações sociais do projeto e das práticas políticas do Estado bolivariano, dos governos Chávez. E o Estado está consumando o que sempre quem detinha a hegemonia consuma: a direçáo, inclusive para a educação. É “[...] expresión rectora del Estado en Educación, en cumplimiento de su función indeclinable y de máximo interés como derecho humano universal y deber social fundamental, inalienable, irrenunciable, y como servicio público que se materializa en las políticas educativas" (VENEZUELA, 2009, p. 4). Essa noção, fundamentada em Luis Beltrán Prieto Figueroa (2006), não é recente, pois, segundo Castellaño, em entrevista concedida, 
"[...] fundamentalmente la derecha y la iglesia católica, han estado en contra de la rectoria del estado en educación porque lógicamente quieren que la rectoria del estado esté en manos privadas o en manos de la iglesia" ${ }^{15}$. Por definição constitucional o Estado venezuelano é democrático e social, de direito e de justiça e, dentro desta definição, todos tem direito a educação (VENEZUELA, 2000). O Estado toma para si a responsabilidade da educação, como função de máximo interesse, dispóe o significado estratégico e prioritário desta nos planos, nas políticas, nos projetos e nos programas, tanto referente à educação formal como não formal, programas de estudo, planejamento, supervisão e administração, financiamento e com outras atividades estatais.

Tratando das competências do Estado Docente, define-se: as garantias atribuídas, tal como "La gratuidad de la educación en todos los centros e instituciones educativas oficiales hasta el pregrado universitario"; o que regula, supervisiona e controla, a exemplo "El obligatorio cumplimiento de la educación en la doctrina de nuestro Libertador Simón Bolívar, el idioma castellano, la historia y la geografía de Venezuela" (VENEZUELA, 2009, p. 5-6); o que promove, integra e facilita a participação social; e o que promove a integração cultural e educativa regional e universal: a) no intercâmbio de teorias e práticas sociais, artísticas, de conhecimento, experiências, saberes populares e ancestrais, que fortaleçam a identidade dos povos latino-americanos, caribenhos, indígenas e afrodescendentes; b) "Desde una concepción de la integración que privilegia la relación geoestratégica con el mundo, respetando la diversidad cultural" (VENEZUELA, 2009, p. 9); c) no reconhecimento e convalidação de títulos e certificados expedidos; d) para a independência e cooperação da investigação científica e tecnológica; e) na criação de uma nova ordem comunicacional para a educação; f) na autorização, orientação, regulação, supervisão e continuação dos convênios multilaterais, bilaterais e de financiamento com entes nacionais e internacionais de caráter público e privado, para a execução de projetos educativos em nível nacional. Isso revela a forma como a Venezuela busca promover a integração latino-americana por meios educativos e culturais, algo que na prática este país já vinha desenvolvendo, no marco dos convênios de educação com Cuba e com outros países da Aliança Bolivariana para os Povos de Nossa América - Tratado de Comércio dos Povos (ALBA-TCP), caso da Bolívia, Equador, Nicarágua e Dominica, entre outros.

Segundo Queipo ${ }^{16}$, em entrevista concedida para esta pesquisa, o Estado: 
[...] promueve la integración cultural y educativa, regional y universal [...] no se puede ver esto sin todo el contexto y verlo integrado a todo los demás que plantea la ley. Verlo en coherencia con los fines de la educación, verlo en coherencia con esa integración que está permeada de todo un bagaje, el plan Simón Bolivar.

Assume a educação como um processo central para promover, fortalecer e difundir os valores culturais destes povos, que vivem e atuam no continente, respeitando o bloco continental de massas mestiça cultural e etnicamente, latino-americana e caribenha, mergulhada na luta de classes e sob um conceito de integração que privilegia a relaçáo geoestratégica com o mundo, ou seja, com países não alinhados aos Estados Unidos e aos ditames ianques, tais como: Irâ, Rússia, China e com os países deste continente, na relação sul-sul, como forma estratégica de resistência e de luta anti-imperialista.

Entre as finalidades da educação na LOE/2009, destaca-se: "Impulsar la integración latinoamericana y caribeña bajo la perspectiva multipolar orientada por el impulso de la democracia participativa [...]" (VENEZUELA, 2009, p. 13). Este fragmento permite localizar um entendimento de integração da América Latina, que se pauta numa perspectiva multipolar e se orienta, entre outros aspectos, pelo impulso da democracia participativa e protagônica, que amplia os mecanismos de participação direta do povo venezuelano, para além dos clássicos que vigoram no liberalismo, e as novas formas de organização popular, tais como os Conselhos Comunais e a emergência das Comunas, mecanismos de participação que demandam novas relações entre Estado e sociedade. $\mathrm{O}$ dispositivo citado acima, que associa à integração da América Latina as finalidades da educação venezuelana, dimensiona a envergadura dessa tarefa, que compóe o entendimento bolivariano do processo integracionista. Essa integração realizada também por meios educativos permeia a formação do sujeito histórico em valores determinados, o que remete, por exemplo, a educaçáo bolivariana concebida no sistema educativo como um todo.

O que se observa é que a educação bolivariana da Venezuela, no período de 1999-2009, expressa o tema da integração latino-americana. Esse "expressa" se revela concretamente em orientaçóes filosóficas do Diseño Curricular del Sistema Educativo Bolivariano, no caráter das Escuelas Bolivarianas, em objetivos e conteúdos curriculares do Liceu Bolivariano, no Sistema Educativo Bolivariano, na definiçáo do que é o Estado Docente e como finalidade da 
educação na LOE/2009, ou seja, nos diferentes documentos oficiais e legais da educação, e, aliás, não apenas nestes.

\section{$\mathrm{O}$ aporte que norteia a integração latino-americana na educação venezuelana}

A orientação integracionista, como parte do ideário bolivariano, está presente, inicialmente, na base legal venezuelana, qual seja na Carta magna aprovada em 1999. Também consta nos programas iniciais de governo - o Programa Econômico de Transição 1999-2000, o Programa Econômico 2000 e o Programa Econômico 2001 - e, posteriormente, nos planos de desenvolvimento econômico e social da nação - o PDES 2001-2007 e o Primeiro Plano Socialista (PPS) 2007-2013. Embora o preâmbulo constitucional e alguns artigos expressem o tema da integraçâo latino-americana, de forma ampla e aberta a proposiçóes futuras, pois a orientação marco, os primeiros programas de governo desenvolvem apenas parcialmente esse aspecto. Isso em parte se deve à instabilidade tanto econômica quanto política pela qual o país passou, especificamente entre 1999-2003, no golpe de Estado e na greve-sabotagem dos empresários petroleiros. A categoria integração da América Latina adquire uma mudança significativa após este período. O PDES já sinalizava a necessidade de um "mundo multipolar", que seria aprofundada no PPS.

Ainda em vigência do primeiro plano, a Venezuela direcionaria sua orientação integracionista, ao entender como nefastos os acordos bilaterais estabelecidos no âmbito da Comunidade Andina das Naçóes (CAN), vinculados aos Estados Unidos, e, em 2006, retira-se do bloco, para pleitear sua entrada no Mercado Comum do Sul (MERCOSUL). A rigor, esta seria uma estratégia política, a fim de dinamizar a economia não apenas venezuelana, mas benéfica também aos países que compóem esse bloco. $\mathrm{Na}$ verdade, além de ampliar a margem de países com quem mantém relaçóes, buscaria, conforme expresso no PPS, participar da construção de um "novo MERCOSUL" (VENEZUELA, 2007c). A mudança política quanto à vinculação a determinados mecanismos integracionistas não rompe, contudo, com o suporte teórico que o país afirma enquanto integração. O que guia o processo de integraçáo que a Venezuela leva a cabo, articulada internamente com a Revolução Bolivariana e externamente em particular via Aliança Bolivariana para os Povos de Nossa América - Tratado de Comércio dos 
Povos (ALBA-TCP), é sempre uma decisão política, quer anti-imperialista, ou, como a partir do PPS, também anticapitalista.

Conforme Villa (2007 apud LOPES; HITNER, 2009), a Venezuela concebe a integração em bases econômicas e políticas, como um processo anticapitalista, coerente com sua visão do Socialismo do Século XXI. A política anti-hegemônica dos governos Chávez requer uma maior integração latino-americana como forma de se firmar no cenário internacional (LOPES; HITNER, 2009). Por isso, a partir de 2001, o governo procura aprofundar as relaçôes com os países da regiáo. Assim, na medida em que se ampliam e se diversificam as relaçôes externas venezuelanas haveria um maior suporte para a construção desse socialismo.

O PPS dedica um espaço significativo à integração latino-americana, pois esta é parte essencial da política externa venezuelana. Também estabelece o substrato teórico dessa integração de caráter bolivariano: solidariedade, complementaridade e cooperação. Uma orientação de integração latinoamericana e caribenha desenvolvida a partir de princípios distintos da lógica liberal, apesar da histórica presença energética, em razão do potencial venezuelano petroleiro. Não expressa centralmente uma integração comercial, mas, sim, uma proposição integracionista que envolve o econômico, político, social e cultural.

No nível da política externa, a Venezuela procura concretizar o que está expresso no PPS. Atua na direção da ALBA-TCP em defesa da integração latinoamericana, que, além de solidária, cooperativa e complementar, incorpora o conceito de justiça. Os outros mecanismos integracionistas a que está vinculada, como a União das Naçóes Sul-Americanas (UNASUL), Comunidade de Estados da América Latina e Caribe (CELAC), MERCOSUL, compóem o que a Venezuela entende como integração, embora não na mesma dimensão que na ALBA-TCP, até porque essa dimensão é resultado dos confrontos de forças no interior de cada mecanismo integracionista, que dão a direção e em razão disso a Venezuela não tem a mesma possibilidade de intervenção. Isso não significa secundarizá-los ou desconsiderá-los, mas entender a correlação de forças e identificar quem detém a hegemonia no interior dos mecanismos integracionistas. Além disso, pode ser uma chave à sobrevivência da ALBA-TCP (2010), que não sobreviverá sozinha nem construirá isoladamente outro projeto de sociedade. Por isso, os mecanismos de integração podem ser instrumentos de difusão do Socialismo do Século XXI. 
A ALBA-TCP é uma nova comunidade de naçóes integradas que aponta para uma uniáo econômica e política, sustentada na união cultural e social, pela diversidade de povos e culturas que integram a região latino-americana e caribenha, pelo passado singular que tem (OBEDIENTE, 2007). Bolívar já defendia que a pátria é a América, mas esta não existe se não estamos integrados. Para isso, porém, é relevante saber o tipo de integração: de fraternidade ou de colonização, pois integração é diferente de subjugação. Ela perpassa múltiplos sentidos: econômico, social, político, cultural, "[...] integrar es mucho más que juntar, es unir sin fusionar. Significa agrupar sin que cada parte pierda su esencia, implica que éstas se beneficien mutuamente" (CAMACHO apud GARCÍA, 2009, p. 59).

A ALBA-TCP (2010) define, como pilares fundamentais da política exterior comum de seus países, a construção da igualdade entre todas as naçóes para um mundo pluripolar, ou seja, a consolidação de espaços, acordos e alianças com países e organizaçóes que contribuam para acabar com a hegemonia imperialista, e a luta contra o intervencionismo e a guerra. Na proposiçấo integracionista grannacional da ALBA-TCP, a articulação internacional soberana, o bloco latino-americano é diferente do isolamento internacional e unipolaridade das relaçóes atuais: dependência ao centro, globalização, desconexão latinoamericana. Configura-se, pois, como resistência e anti-imperialismo desde el sur e demais países politicamente náo alinhados ao american dream of live. Conforme Spilimbergo (2008), a condiçấo do imperialismo, sustentada pela exploração dos países dependentes, contraditoriamente alimenta a possibilidade de concretizaçáo do projeto integracionista. Resistência e luta anti-imperialista sáo parte do processo que alguns países latino-americanos têm ensejado no atual século, objetivando a realização da naçáo fragmentada e inacabada, a Pátria Grande, que tem a unidade como via para um projeto de emancipação.

O processo integracionista da ALBA-TCP, segundo Noya ${ }^{17}$, "un bloque geopolítico contrahegemónico", ou regionalismo contra-hegemônico na América Latina e Caribe (MUHR, 2010), ganha força na medida em que esses países se identificam com a orientaçáo bolivariana, tencionando numa perspectiva de mudanças com ruptura, dada pela e para a classe trabalhadora latino-americana: boliviana, argentina, peruana, brasileira, cubana, venezuelana, chilena, uruguaia, equatoriana, enfim, das nações que compóem a América Latina, uma vez que não há o tipo ideal latino-americano. $\mathrm{Na}$ realidade, o que existem são classes sociais latino-americanas: classe proprietária latino-americana e classe 
trabalhadora latino-americana. Ao se aproximar da "essência" latino-americana, enquanto classe, indica-se também que, para compreender esse povo atravessado pela dependência, conforme Molina (2007, p. 178), é preciso ter presentes as afinidades geoculturais, históricas, étnico-raciais, religiosas, artísticas e de outras índoles, de nossos povos, ou seja, a grande diversidade de nossas raízes, porque "[...] la tendencia unipolar que sigue esa ola de globalización cultural hegemônica [...] anula la principal riqueza del desarrollo humano: la diversidad".

É, no entanto, reconhecível que a integração da América Latina guarda uma contradiçẫo desde o período colonial, de conquista das naçōes e diferenças socioeconômicas. Conforme Obediente (2007), a integração dos povos sulamericanos remonta à colonização, em que "los latinoamericanos habíamos sido condenados a vivir cien ańos de soledad" (MÁRQUEZ apud OBEDIENTE, 2007, p. 75-76), pois "[...] la interpretación de nuestra realidad a través de patrones que no son los nuestros, sólo servirá para hacernos más desconocidos, menos libres, más solitarios" (OBEDIENTE, 2007, p. 76). Além disso, de fato, a integração da América Latina, que compreende um projeto próprio de sociedade, cultura e identidade, para incorporar-se ao mundo como sujeitos históricos não é de fácil realização. Os interesses de classes e segmentos sociais, em alguns mecanismos de integração, materializam-se numa integração setorizada: saúde, transporte, justiça, indústria, cultura, agricultura, segurança e educação. Ideologicamente, essa integração nega a totalidade da realidade, que compóe o desenvolvimento, pois se trata de uma estratégia comum de exploração do capital sobre o trabalho na região, otimizando os espaços privilegiados, garantindo, no âmbito do bloco, a reprodução e a acumulação capitalista. Com isso, ela gerencia a contradição estrutural que configura o desenvolvimento desigual e combinado do modo de produção capitalista (BARBOZA, 2009).

O processo de integração regional é parte da dinâmica desenvolvida na economia mundial, ao movimento de formação de blocos entre países com interesses afins. Nos países desenvolvidos, do centro capitalista, esse processo os torna ainda mais poderosos e fortes. Já no que tange aos países dependentes e periféricos da América Latina, o processo integracionista é posto, desde os anos 1950, como "lança para o desenvolvimento" e, em diferentes matizes, necessário à sobrevivência dos países latino-americanos e caribenhos ${ }^{18}$. É, portanto, problemático cogitar uma integraçáo diferente desses processos ainda que, na contradição, para além de sobreviver, em última instância, se interesse por um projeto voltado à libertaçáo dos povos, de emancipação, que a unidade - e a 
não incorporação e submissão - poderia contribuir. Faz-se necessário, dentro da diversidade de povos e culturas que integram o continente, do passado singular que têm,

[...] reelaborar un proyecto proprio de sociedad y cultura, de identidad, no para aislarnos del resto del mundo, sino para incorporarnos activamente a él, como sujetos históricos de verdad; y no para dar la espalda a la modernidad, sino para definir el perfil de la que nosotros queremos, de acuerdo con nuestros proyectos e nuestros intereses. (CUEVAS, 1991 apud OBEDIENTE, 2007, p. 75).

O lema nuestro norte es el sur pretende ressaltar as prioridades da integração latino-americana colocando nosso "norte" nos países da América Latina e Caribe (PARLATINO, [20--]). Embora haja "sul no norte e norte no sul", segundo Espinós (2009), o Norte e o Sul não são somente territoriais, significam classes sociais, grupos sociais, organizaçóes e movimentos sociais. Seus processos de integração, em tese, correspondem às necessidades antagônicas. Se quisermos outro tipo de sociedade, também queremos outro tipo de economia, outro tipo de processo de integração, que, no limite, indique a ruptura:

La unidad de nuestros pueblos latinoamericanos tiene por objetivo elemental e inmediato romper las cadenas de la opresión imperialista, reconquistar la plena independencia económica, política y cultural [...]. Pero el mundo de hoy las revoluciones anti-imperialistas tienen contenido socialista, solamente pueden completar sus objetivos, realizarse plenamente y satisfacer las aspiraciones de la clase obrera y del pueblo, marchando hacia el socialismo. (DÍAZ, 2006a, p. 49).

Ou seja, a unidade de nossos povos é parte dessa frente socialista. Isso não significa a simultaneidade das revoluçóes nem que elas tenham formas e caminhos idênticos. A experiência histórica e as diferenças no desenvolvimento econômico dos diversos países da América Latina e Caribe indicam que vivemos processos diferentes em tempo, espaço e condiçōes, mas é necessário que exista plena solidariedade e ajuda mútua para que tenha êxito (DÍAZ, 2006b). 
Toda essa percepção, em conjunto, vem afirmar que a integração latinoamericana, para a Venezuela, é uma estratégia diplomática importante para a difusão do Socialismo do Século XXI. As açôes diplomáticas, que envolvem apenas os países latino-americanos e parte deles, como a ALBA-TCP, são instrumentos fundamentais para promover a integração latino-americana, e como parte desse movimento se difundem as orientações teóricas e as práticas políticas para a construção socialista, isto é, a integração seria um instrumento para a consubstanciação futura do projeto do Socialismo do Século XXI, desenvolvido a partir do PPS, e que passaria a orientar a formaçáo do novo homem. Essa hipótese afirma-se no fato de que o governo Chávez precisa de aliados na América Latina, aliados que compartilhem uma mesma visão integracionista, pois, se o projeto bolivariano ficar isolado na Venezuela, ele fracassará. A integração da América Latina, assim como o socialismo, não pode ser realizada em um só país, pois requer a unidade latino-americana. Segundo Carmona (2007), a grande tarefa da luta socialista na região seria compartilhar a direção dos projetos nacionais próprios de cada experiência, como a venezuelana, equatoriana e boliviana, num movimento integracionista que permita ampliar cada vez mais a margem de ruptura com o projeto neoliberal.

O Socialismo do Século XXI não será possível sem a integração, pois se afirmará na unidade e na diversidade latino-americana. Esse socialismo e a integração da América Latina encontram-se na unidade e na diversidade, que, segundo Hernández (2006), busca o pensamento latino-americano, bolivariano, fonte do socialismo venezuelano, que estão nas três raízes: Bolívar, Rodríguez e Zamora. Além disso, de acordo com o PPS, esse socialismo venezuelano também tem suas raízes nas correntes humanistas (VENEZUELA, 2007d). A integração continental é imprescindível na atualidade, quando o imperialismo busca desunir para submeter. Além disso, conforme Faría (2006), o aprofundamento da integração com economias latino-americanas é de vital significado na ausência de um campo socialista, pois argumenta que a economia venezuelana náo poderá se desenvolver com base no intercâmbio comercial dominado pelas corporaçóes transnacionais, por isso a integraçáo latino-americana se converte em condição indispensável para a sobrevivência do projeto socialista.

As práticas políticas soberanas da maioria dos países da América Latina revelam que a integração defendida pela Venezuela só tem sentido em razão da soberania, definida no dispositivo da Constituição de 1999, que afirma ser a Venezuela um país soberano. Pode-se afirmar que a integraçáo posta em 
prática pela Venezuela se fundamenta numa integração não homogênea, não padronizada, mas da unidade na diversidade. Esse país defende a soberania e também defende que os países com quem se relaciona e quer se integrar sejam soberanos. Consequentemente, essa diversidade, é o socialismo venezuelano, por isso o Socialismo do Século XXI pode ser o boliviano, equatoriano, nicaraguense, argentino, brasileiro etc. Vai ser de acordo com a história e de acordo com as particularidades internas, da política, da economia e da cultura, como um processo em construçáo e que, portanto, não está acabado. $\mathrm{O}$ mundo pluripolar, as estratégias de integração sur-sur, com o mundo árabe, a Coreia do Norte, a Rússia e a Bielo Rússia, rompe com o imperialismo e, no mesmo movimento, cria condiçóes de integraçáo com parte do mundo dependente numa outra estratégia geopolítica que contribui decisivamente com a integração latino-americana. Na contradição, o mundo globalizado nos permite globalizar entre nós o "mundo" dependente, e a integração da América Latina é parte desse movimento, e integrada, tendencialmente, poderia "exportar" o Socialismo do Século XXI para o sur-sur.

Em razão de que a educação escolar de forma mediatizada é parte desse movimento das relaçôes sociais, a soberania está vinculada estreitamente ao conceito de Estado Docente, que intervém, direciona e exerce a reitoria da educação. Isso permite estabelecer políticas de Estado que se traduzam em mecanismos de integraçáo no interior da escola. O Estado que emerge na idade moderna e também esse Estado venezuelano, neste momento da história, cumprirá o seu papel hegemônico: direcionar a educação escolar nesse país. Por isso, o PPS indica a necessidade de adequar a educação ao plano socialista.

A educação bolivariana implementada nos governos Chávez é parte do projeto de nação orientada para refundar a república e que, no momento, direciona-se à superação do capitalismo e à construção do Socialismo do Século XXI e não pode ser compreendida descolada desse contexto. Dentre os princípios constitucionais está à motivação de refundar a república para estabelecer uma sociedade democrática, baseada na educação e no trabalho como processos fundamentais para garantir os fins do Estado. A LOE/2009, expressão jurídica da vontade do Estado, enquanto orientaçáo marco da educação venezuelana, faz parte, juntamente com o trabalho, dessa refundação.

A educação, como instrumento na formação do homem venezuelano, latino-americano, que entenda a integração como importante, uma vez que 
o caráter bolivariano das escolas recorda que somos latino-americanos e caribenhos, que temos que ver e compreender o Sul, a América Central e as Antilhas, pois nossa perspectiva é compartilhada e as possibilidades de futuro comum estâo amarradas à capacidade integracionista (VENEZUELA, 2006). A integração se torna uma estratégia pedagógica para a formação do homem emancipado, é um elemento para o socialismo e o dispositivo legal que trata das finalidades da educação também vai nessa direção.

Os argumentos mencionados acima confirmam que a integração da América Latina assumida pela Venezuela, que se expressa também no conjunto dos documentos oficiais e legais educacionais, adquire maior relevância política e pedagógica na LOE/2009. Isso se traduz num instrumento fundamental para a formação do "homem novo" venezuelano, latino-americano, que, imbuído dessa noção de integração, contribuirá para a construção do projeto do Socialismo do Século XXI.

No PPS, a relação entre educação e integração latino-americana está inscrita nos objetivos de promover uma ética, cultura e educação libertadoras e solidárias e aprofundar a solidariedade com os excluídos da América Latina e Caribe. Para concretizar esses objetivos, o PPS propóe as seguintes estratégias de Políticas Educacionais: aprofunda a universalizaçáo da educação bolivariana, por meio da ampliação da cobertura da matrícula, com a garantia da permanência e conclusão, buscando, entre outras estratégias, a adequação do sistema educativo ao modelo socialista. Também massifica uma cultura que fortaleça a identidade nacional, latino-americana e caribenha e fomenta a participação organizada do povo no planejamento da produção e socialização equitativa dos excedentes (VENEZUELA, 2007c).

Interessa ao trabalhador esse alargamento da educação e a luta pela construção de Políticas Educacionais inclusivas voltadas à universalização da educação em todos os níveis. A recente história da educação bolivariana na Venezuela tem apontado para a universalização inclusive da educação universitária ${ }^{19}$ e explicita o intuito de fortalecê-la como espaço de unidade latino-americana e caribenha, solidariedade e cooperação com os povos do mundo, um dos objetivos da Missão Alma Mater, consoante ao Plano setorial de Educação Universitária 2008-2013. O país cria a Universidade Nacional Experimental dos Povos do Sul (UNISUL), visando impulsionar uma nova geopolítica internacional a partir do Sul e a finalidade de promover a uniấo de seus povos (VENEZUELA, 2010). 
Conforme Damiani e Bolívar (2007), a Venezuela tem assumido, no processo de mudança, uma opção alternativa de espírito socialista centrada na integração latino-americana, reconhecendo-nos na história em comum e resgatando o ímpeto de luta anti-imperialista pela emancipaçáo. Consciência social, memória histórica, identidade cultural e integração anti-imperialista são princípios fundamentais, fios condutores de uma pedagogia da emancipação, do processo de formação e de desenvolvimento revolucionário. Essa pedagogia perpassa desde o projeto republicano de moral e luzes e uma educação popular, de Bolívar, ao projeto de educação popular do mestre Rodríguez, à resistência e à educação popular em Martí, à educaçáo na revolução e ao socialismo como projeto anticapitalista em Mariátegui ${ }^{20}$, ao socialismo e ao homem em Cuba e à universidade em $\mathrm{Che}^{21}$, à unidade da cultura em Gabriela Mistral ${ }^{22}$, entre outros.

\section{Considerações finais}

Como a realidade não é estática foi preciso a apreensão do seu movimento histórico. A explicação só pode ocorrer com o acúmulo provisório do todo, assim, depreendeu-se que a Política Educacional venezuelana revela concretamente o objeto deste estudo, pois de forma mediada e com contradições a educação, como parte das relações sociais, é espaço de reprodução dessas relações e/ou de movimentos contra hegemônicos significativos.

Entendemos que as bases legais, os documentos oficiais analisados dos governos Chávez, as práticas econômicas e políticas para a integração da América Latina se configuram como um enfrentamento em relação às potências do mundo globalizado. O projeto venezuelano na direção da integração da regiâo está diametralmente oposto às novas demandas da internacionalização do capital. A integração bolivariana e a formação do sujeito histórico em sua base apontam, no limite, para a construçáo de uma nova sociedade diferente da burguesa. As Políticas Educacionais venezuelanas estáo articuladas a essa forma de integração da América Latina e a educação bolivariana teria um papel na difusão da formação da integração latino-americana que a Venezuela defende. A educação escolar bolivariana, em última instância, reproduz a posição hegemônica, apesar de todas as contradiçôes. Mas, quando é que a educação não teve caráter ideológico?

Conforme Felipe Figueroa (2006), o socialismo supóe o desenvolvimento integral do indivíduo e as missóes, e o novo sistema educativo venezuelano pode 
contribuir para esse desenvolvimento, que não é um ato único, mas resultado de um longo processo de evolução e educação, que começa a edificar-se com a herança do capitalismo. Pensando a partir de Lênin (apud FIGUEROA, F., 2006), é inegável que o caráter da Escola é de classe, bem como o conteúdo do ensino é ideológico, não sendo, portanto, neutro ou indeterminado. À escola capitalista - e o que a sustenta -, que reproduz de modo específico determinada forma de produção, cabe, pois, a categoria de superação: "A superação é um movimento transformador que implica ao mesmo tempo conservaçáo e destruição" (SAES, 2005, p. 32). Implica conservação no sentido de a sociedade socialista proletarizar a educação escolar: "fazer com que o conjunto da sociedade - isto é, as massas trabalhadoras - tenham de fato acesso à ciência e à cultura, rompendo assim o monopólio exercido pela classe média sobre ambas" (SAES, 2005, p. 32). E implica ruptura com a ideologia pequeno-burguesa, que nega tratar em termos dialéticos a relação entre conhecimento e prática social (SAES, 2005).

As Políticas Sociais massivas de inclusão desenvolvidas pelos governos Chávez parecem apontar na direção de superação, trabalhada por Saes (2005). Grande parte da população esteve historicamente à margem de diversos bens sociais, como educação, saúde, alimentação, habitação, comunicação, entre outros. E, ao mesmo tempo em que, pela educação bolivariana ou pelas Missóes Educativas e Sociais, tem acesso à ciência e à cultura, a nova geometria do poder permite mecanismos distintos de participaçáo, inclusive na formulação de políticas. Engendra-se, dessa forma, uma nova configuração no país, após a vigência puntifijista.

A criação do "novo homem" é o objetivo de longo prazo de toda educação socialista, cuja escola objetiva a formação do homem político e a formação do homem trabalhador, garantindo a possibilidade de uma educação contínua, que "[...] visa propiciar aos indivíduos uma grande mobilidade profissional [...] o objetivo de favorecer a realizaçáo da aspiraçáo humana à diversificação das atividades" (SAES, 2005, p. 39) - mas esse é um objetivo de longo prazo, inclusive para a Venezuela.

Há uma tensão latente entre a escola ser determinada, na lógica da totalidade, da luta de classes, e determinar, "criar o homem novo". Apontase a escola integrada a um conjunto de transformaçôes sociais, políticas e econômicas, bem como o papel que lhe cabe, dado o acesso universal. Exige-se um currículo histórico, organização do trabalho pedagógico e outra 
pedagogia, fundamentalmente latino-americana e caribenha, e não de cunho internacionalista. Nesse contexto determinado, a diferença da escola venezuelana começa a ser ensejada e seu arcabouço teórico, metodológico, curricular e, em suma, seus fundamentos podem ser ressignificados ou inaugurais.

A educação bolivariana da Venezuela, portanto, assim como os diferentes fenômenos históricos, não está pronta e acabada, mas permeada por lutas e confrontos. A educação é um espaço de disputa, seja no movimento de transformação ou de conservação social e pode se constituir, por meio de suas diversas práticas, formais ou não, em instrumento de tomada de consciência de classe para si ou de reproduçáo do establishment.

Afirma-se, tendo ciência da provisoriedade do estudo realizado, que a categoria integração da América Latina na LOE/2009 pode se constituir como caminho de difusão da integração com viés proletário, vinculada à superação da exploração capitalista e à construção do Socialismo do Século XXI, que interessa ao trabalhador latino-americano. Assim, uma nova práxis social e educacional, latino-americana e caribenha, pode, a partir dos marcos concretos desta latitude, da história das naçóes latino-americanas e das lutas travadas até hoje, cimentar uma revolução genuína nos termos da "pequena humanidade", rumo a um projeto emancipador. E que, finalmente, o exercício da crítica e da luta da classe trabalhadora apreenda a centralidade da unidade na diversidade, já desvelada outrora.

La unidad de los pueblos de Nuestra América contra al imperialismo,
es la columna vertebral del proyecto de emancipación.
Nadie libera a otro y nadie puede liberarse solo.
Los pueblos se liberan en comunión,
es la gran lección de la historia latinoamericana.

Che.

\section{Notas}

${ }^{1}$ Este artigo é resultado da pesquisa desenvolvida no Programa de PósGraduação Stricto Sensu em Educação - nível de Mestrado/PPGE, da Universidade Estadual do Oeste do Paraná (UNIOESTE), campus de Cascavel. A pesquisa contou com bolsa da Demanda Social da CAPES.

${ }^{2}$ Da passagem de Oswald de Andrade (2001, p. 43-44), "Nenhuma 
fórmula para a Contemporânea Expressão do mundo. Ver com olhos livres. [...] $\mathrm{O}$ contrapeso da originalidade nativa para inutilizar a adesão acadêmica”.

${ }^{3}$ Como versa o poema de Mário Benedetti (1993), “[...] mas aqui em baixo, abaixo perto das raízes é onde a memória nenhuma recordação omite e há quem se recuse de morrer e há quem se esqueça de viver e assim entre todos se consegue o que era um impossível que todo mundo saiba que o sul também existe".

${ }^{4}$ Simón Rodríguez (1771-1854), educador venezuelano e conhecedor da sociedade hispano-americana. Estudioso de Rousseau e de outros pensadores da Ilustração, como Montesquieu e Voltaire. Acompanhou o processo de independência norte-americana e a Revolução Francesa, forjando seu espírito de rebelião. Foi professor do Libertador, Simón Bolívar. Lutou contra a coroa espanhola, foi perseguido e teve que deixar seu país de origem, deslocando-se para a Jamaica, onde mudou seu nome para Samuel Robinson, em alusão a seu tio Sam e ao personagem Robinson Crusoe da história de Daniel Defoe. Dentre seus escritos destaca-se Sociedades Americanas (1828). Suas obras completas foram publicadas em dois tomos, em 1999, na Venezuela (TAVARES, 2013; PÁEZ; ÁLVAREZ, 2007).

${ }^{5}$ Simón Bolívar (1783-1830), militar e político venezuelano, lutou nos processos de libertação da Venezuela, Colômbia, Equador, Peru, Bolívia e Panamá. Influenciado pela literatura da Revolução Francesa, era um anticolonialista, republicano e abolicionista (PÁEZ; ÁLVAREZ, 2007). As ideias educativas de Bolívar têm origem nos princípios da Revolução Francesa, por isso defende uma educação pública, dirigida pelo governo.

${ }^{6}$ Tais como: o Programa de Alimentação Escolar, o desenvolvimento de Projetos de Aprendizagem nas Escolas Bolivarianas, de Projetos Produtivos nas Escolas Técnicas Robinsonianas, de Projetos Educativos Integrais Comunitários (define estratégias de gestão escolar), realização de Seminários de Desenvolvimento Endógeno nos Liceus, Plano Integral, entre outros. Também seriam criadas, paulatinamente, um total de 28 Missóes Sociais, para atender problemáticas sociais, como: saúde, alimentação, habitação, desenvolvimento sociocomunitário e cultural, indígena, entre outros. 
${ }^{7}$ Com uma atenção assistencial, em saúde, nutrição, recreação, cultural e legal.

${ }^{8}$ As Missões Educativas são meios para garantir a universalização da educaçáo e atendem os jovens e adultos que estão fora da faixa etária, na relação entre idade e série do nível de ensino. A Missão Robinson é uma homenagem a Simón Rodriguez, que ao residir na Jamaica, em 1797, mudou seu nome para Samuel Robinson. Os alunos matriculados nessa missão são chamados de "patriotas". A Missão Ribas referencia José Félix Ribas (1775-1815), militar que participou das lutas pela libertação venezuelana e venceu uma batalha importante para o processo emancipatório do país. Os alunos que a integram são chamados de "vencedores". A Missão Sucre remete a Antonio José de Sucre (17951830), herói da independência da Venezuela. Os alunos dessa missão são denominados de "triunfadores" pelo significado do triunfo na luta pela libertação e por conseguirem atingir esse nível de formação educacional (NOGUEIRA; RIZZOTTO, 2009).

${ }^{9}$ Francisco de Miranda (1750-1816), militar venezuelano que lutou pela independência da América, de uma forma geral, e da Venezuela, em particular. Foi tenente dos exércitos quando da independência do seu país, em 1811 (PÁEZ; ÁLVAREZ, 2007).

${ }^{10}$ Ezequiel Zamora (1817-1860), militar e político venezuelano, é um dos protagonistas da Guerra Federal, também lutou a favor dos camponeses pela Reforma Agrária. É expressão do ideário da igualdade social na mentalidade coletiva, conhecido como o General do povo soberano (ZAMORA; BOLÍVAR, 2009).

${ }^{11}$ Luis Beltrán Prieto Figueroa (1902-1993), educador e político venezuelano, lutou pelos direitos do povo para que a educaçáo respondesse ao interesse da maioria, fosse democrática, gratuita e obrigatória. É considerado o Mestre dos mestres. Seu pensamento foi influenciado pelo ideário de John Dewey, bem como pela pedagogia humanista de Paulo Freire. Fundou e foi o primeiro presidente da Federação Venezuelana de Professores (1936). Foi designado Ministro de Educação (1948). Redator e promotor do Projeto de Lei Orgânica de Educação Nacional. Fundou o Instituto Nacional de Cooperação Educativa (INCE), convertido pelo presidente Hugo Rafael Chávez Frías em INCES, agregando o termo 
Socialista a sua denominação. Dentre suas obras destacam-se: $O$ Estado Docente, O Estado e a Educação na América Latina e Princípios Gerais da Educação (FUENMAYOR et al., 2009).

12 Belén Sanjuán (1917-2004), professora e escritora venezuelana, militante do Partido Comunista da Venezuela, lutou pela educação como um processo integral e criou escolas experimentais em Caracas. Fundou, junto com Amalia Romero, o Instituto de Educação Integral (1955), a fim de unir sua visão de educação aos princípios de Simón Rodríguez e ensinar para a liberdade e a responsabilidade, tornando-se uma República Escolar (BRACHO, 2005).

${ }^{13}$ José Martí (1853-1895), escritor e jornalista cubano, revolucionário da independência do país em relação à Espanha, fundador do Partido Revolucionário Cubano (1892) e do jornal Pátria. Para ele, a luta deveria ser uma transformação nos aspectos econômico, político e social. $\mathrm{O}$ entendimento político de Martí sobre nossa América tem desdobramentos na educação, pois educaçáo e projeto de sociedade são parte de um mesmo processo: nova sociedade, novo homem, que a partir da realidade latinoamericano ensine sua história (MORETTI, 2010). Seus ideais, junto com o marxismo-leninismo, guiam a política de Cuba até hoje. Entre suas obras destacam-se: Nossa América: antologia e Educação em Nossa América.

${ }^{14}$ Paulo Freire (1921-1997), educador brasileiro, conhecido principalmente pelo seu método de alfabetizaçáo de adultos. Desenvolveu um pensamento pedagógico com caráter político progressista. Entendia que o objetivo da educação é conscientizar o aluno, perceber sua situação de oprimido e agir por sua libertação. Na história da educação brasileira é a principal referência da Pedagogia Libertadora. Sua educação popular e metodologia influenciaram professores da América Latina e África. Dentre suas obras destaca-se Pedagogia do Oprimido. Partes de suas contribuições foram compiladas por Souza (2001).

${ }^{15}$ Entrevista concedida ao autor em Caracas, em 26 de outubro de 2010. Maria Egilda Castellaño é professora titular jubilada da UCV, reitora fundadora da UBV, foi vice-ministra da Educação Superior e, atualmente, é coordenadora do despacho do Ministério do Poder Popular para a Educação Universitária. 
${ }^{16}$ Entrevista concedida ao autor em Caracas, em 6 de outubro de 2010. Maria de Queipo é deputada e coordenadora da Comissão de Educação, Cultura, Esportes e Recreação.

17 Entrevista concedida ao autor em Caracas, em 19 de outubro de 2010. Xoan Noya é deputado do grupo venezuelano do PARLATINO, responsável pelo convênio de cooperação internacional da ALBA do Ministério do Poder Popular para a Educação Universitária (MPPEU) e membro da juventude do Partido Socialista Unido da Venezuela (PSUV) responsável pelas relaçóes internacionais.

${ }^{18}$ De acordo com Estay (2001), a integração dos anos 1950 e 1970 propiciava condiçóes para a ampliação dos mercados e para novas etapas do processo de substituição de importaçôes, como forma de desenvolvimento. Essa ideia não corresponde ao projeto neoliberal dos anos 1980 e 1990, de um regionalismo aberto, de derrubada das barreiras nacionais e liberalização comercial, fluxo de mercadorias e pessoas. A globalização é compatível com o projeto "integracionista" da ALCA e dos TLCs, que querem a partir de fora incorporar e submeter economias menores. E este, por sua vez, também não corresponde com as proposiçóes integracionistas de alguns países que, na primeira década do século XXI, deram uma guinada à esquerda e pretendem dar outro caráter à integração.

${ }^{19}$ Para o ano letivo 2009-2010 a taxa bruta de matrícula da educação universitária foi de $83 \%$, segundo dados divulgados pela Organizaçáo das Naçōes Unidas para a Educação, Ciência e Cultura. E a Venezuela ocuparia o $5^{\circ}$ lugar mundial e o $2^{\circ}$ na América Latina, com taxa de cerca de 2,5 vezes a média regional (UNESCO, 2009).

${ }^{20}$ José Carlos Mariátegui (1894-1930), escritor e jornalista peruano, fundador e principal dirigente do Partido Socialista e da Central Geral dos Trabalhadores do Peru. Um dos mais influentes pensadores do marxismo latino-americano no século XX. Defendeu a educaçáo popular e o socialismo indo-americano, como projeto anticapitalista de resistência, construído de forma própria. Dentre suas obras destacam-se: Sete ensaios sobre a realidade peruana, Temas de nossa América, Temas de Educação e Defesa do marxismo, disponibilizadas online e/ou parte compiladas (ESCORSIM, 2006). 
${ }^{21}$ Ernesto "Che" Guevara (1928-1967), médico e revolucionário argentino, lutou contra a pobreza e as injustiças, percorrendo os países latino-americanos e serviu a causa em distintas frentes, entre elas a militar (PÁEZ; ÁLVAREZ, 2007).

${ }^{22}$ Gabriela Mistral (1889-1957), pseudônimo de Lucila de María del Perpetuo Socorro Godoy, poetisa, educadora, diplomata e feminista chilena. Lutou pela educação, resistência e integração indo-americana. Alguns de seus textos foram compilados por Damiani e Bolívar (2007).

\section{REFERÊNCIAS}

ALBA-TCP. Construyendo un Mundo Pluripolar: cumbres 2004-2010. Caracas: Secretaria Ejecutiva del ALBA-TCP, 2010.

ANDRADE, Oswald. A utopia antropofágica. São Paulo: Globo, 2001. (Obras Completas).

ARAQUE, Alí Rodríguez; ROJAS, Alberto Müller. Ideas socioeconómicas y políticas para debatir el socialismo venezolano. In: MAYA, Margarita López (Ed.). Ideas para debatir el Socialismo del Siglo XXI. Caracas: Editorial ALFA, 2007. v. 2.

BARBOZA, Mário de Jesus. Política de Educação nos planos do Setor Educacional do Mercosul: a educação como elemento de integração de desenvolvimento regional. 2009. Dissertação (Mestrado em Educação) Universidade Estadual do Oeste do Paraná, Cascavel, PR, 2009.

BENEDETTI, Mario. El Sur tambien existe. In: BENEDETTI, Mario. Preguntas al azar (poesia). Buenos Aires: Seix Barral, 1993.

BOLIVAR, Simón. Discurso de Angostura. 13 de marzo de 1819. Cuadernos de formación ideológica, Caracas, n. 1, ago. 2009.

BRACHO, América. La Educación integral en el pensamiento de Belén San Juan. Caracas: Ministerio de Educación y Deporte, 2005.

CARMONA, Ronaldo. Características da nova luta pelo Socialismo na América Latina. Princípios, São Paulo, n. 92, p. 86-89, out./nov. 2007. 
CASANOVA, Ramón. Democracia e Políticas Sociais na transição venezuelana: entre o capitalismo assistencial e a democracia socialista. Tradução de Viviam Nálio Matias de Faria). In: BORGES, Liliam Faria Porto; MAZZUCO, Neiva Gallina (Org.). Democracia e politicas sociais na América Latina. São Paulo: Xamã, 2009.

DAMIANI, Luis; BOLÍVAR, Omaira. Pensamiento pedagógico emancipador latinoamericano: por una universidad popular y socialista de la revolución venezolana. Caracas: UBV, 2007.

DÍAZ, Pedro Ortega. El congreso de Panamá y la unidad latinoamericana. Caracas: El Tapial, 2006a.

DÍAZ, Pedro Ortega. Socialismo para el siglo XXI. In: VENEZUELA. Ministerio de la Cultura. El Socialismo en el siglo XXI: Trece ensayos sobre el tema. Caracas: Fundación Editorial El perro y la rana, 2006b. (Compilación Instituto de Altos Estudios Políticos y Sociales Bolívar-Marx).

ESCORSIM, Leila. Mariátegui: vida e obra. São Paulo: Expressão Popular, 2006.

ESPINÓS, José Déniz. La crisis económica mundial y la integración regional latinoamericana. In: KATZ, Claudio. Conferencia Internacional de economía politica: respuestas del Sur a la crisis económica mundial. Caracas: Centro Internacional Miranda, 2009.

ESTAY, Jaime. La "vieja” y la nueva integración. In: PARLATINO. Cumbre de la Deuda Social y la Integración Latinoamericana. Caracas: Melvin, 2001. $1 \mathrm{v}$.

FARÍA, Jesús G. La economía política de la transición al socialismo. In: VENEZUELA. Ministerio de la Cultura. El Socialismo en el siglo XXI: trece ensayos sobre el tema. Caracas: Fundación Editorial El Perro y la Rana, 2006.

FIGUEROA, Felipe. Apuntes sobre el socialismo. In: VENEZUELA. Ministerio de la Cultura. El Socialismo en el siglo XXI: trece ensayos sobre el tema. Caracas: Fundación Editorial El Perro y La Rana, 2006.

FIGUEROA, Luis Beltrán Prieto. El Estado docente. Caracas: Fundación Biblioteca Ayacucho, 2006. (Colección Claves de América, n. 30). 
FUENMAYOR, Elsa et al. Descripción de las Ideas Pedagógicas de "Luis Beltrán Prieto Figueroa". Revista Científica Electrónica de Ciencias Humanas, Caracas, v. 5, n. 13, p. 73-85, 2009. Disponível em: <http://www.redalyc. org/articulo.oa?id=70911922007>. Acesso em: 17 mar. 2013.

GARCÍA, Joaquín Torres. Universalismo Constructivo. Buenos Aires: Poseidón, 1941.

GARCÍA, Luis Britto. Nuestra integración. In: GARCÍA, Luis Britto. América Nuestra: integración y revolución. Caracas: Fondo Cultural del ALBA, 2009. v. 2.

GIORDANI, Jorge. La transición venezolana al socialismo. Caracas: Vadell Hermanos, 2009.

HERNÁNDEZ, Mary Pili. ¿¿Qué es el Socialismo del siglo XXI? Aporrea, Caracas, 13 dez. 2006. Disponível em: <http://www.aporrea.org/ideologia/ a28332.html>. Acesso em: 23 ago. 2010.

JÁUREGUI, Luis Bravo. La educación en tiempos de Chávez: una revisión crítica y académicamente orientada del proceso de la educación nacional a partir de 1999. Caracas: El Nacional, 2006.

LOPES, Rodrigo Herrero; HITNER, Verena. Venezuela: o Papel dos Processos de Integração para a Manutenção do Governo Chávez. Cadernos PROLAM/USP, São Paulo, ano 8, v. 2, p. 163-181, 2009.

MANZUR, Juan Carlos Morales. Educación para la integración latinoamericana: propuestas y retos. In: PALACIOS, Juan Manuel Sandoval; FLORES, Raquel Álvarez de (Coord.). Integración latinoamericana, fronteras y migración: los casos de México y Venezuela. México: Plaza y Valdés, 2005.

MOLINA, Ernesto. Estructuralismo, dependencia, integración y socialismo. In: MOLINA, Ernesto. En busca de una teoría crítica para el desarrollo del América Latina. Caracas: Fundación Editorial El Perro y la Rana, 2005.

MORETTI, Cheron Zanini. O coração em Cuba e a alma na América Latina: a insurgência como princípio educativo em José Martí. In: ENCONTRO DE PESQUISA EM EDUCAÇÃO DA REGIÃO SUL, 8., 2010, Londrina. Anais... Londrina: UEL, 2010.

MUHR, Thomas. Venezuela e ALBA: regionalismo contra-hegemónico e ensino superior para todos. Educação e Pesquisa, São Paulo, v. 36, n. 2, 611-627. 
NOGUEIRA, Francis Mary Guimarães; RIZZOTTO, Maria Lucia Frizon. Democratização da educação escolar: as Missões Robinson, Ribas e Sucre e o Estado venezuelano inscrito na Constituição de 1999. In: BORGES, Liliam Faria Porto; MAZZUCO, Neiva Gallina (Org.). Democracia e politicas sociais na América Latina. São Paulo: Xamã, 2009.

OBEDIENTE, Mario Sanoja. Memorias para la integración: ensayo sobre la diversidad, la unidad histórica y el futuro político de Sudamérica y el Caribe. Caracas: Monte Ávila Editores Latinoamericana, 2007.

PÁEZ, Sandra; ÁLVAREZ, Edgar. Libertadores: personajes que cambiaron la historia de latinoamerica. Caracas: Orinoco, 2007.

PARLATINO. ;Construyendo el ALBA! Nuestro norte es el sur. Caracas: Estudios Sancho, [20--].

PIVIDAL, Francisco. Lo que Bolivar no hizo, está todavia por hacer en América. Cuadernos de formación ideológica, Caracas, n. 1, ago. 2009.

SAES, Décio Azevedo Marques de. Educação e socialismo. In: NETO, Benedito Moraes; GALVÃO, Andréia (Org.). Marxismo e socialismo no século XXI. Campinas, UNICAMP/IFCH: Xamã, 2005.

SOLIS, Luis Rubilar. La revolución bolivariana y la educación en Venezuela. Santiago: UMCE, 2005. Disponível em <http://www.umce.cl/luruso/la_ revolucion_bolivariana_educacion_venezuela.doc>. Acesso em: 8 set. 2010.

SOUZA, Ana Inês et al. (Org.). Paulo Freire: vida e obra. São Paulo: Expressão Popular, 2001.

SPILIMBERGO, Jorge Enea. A questão nacional em Marx. Florianópolis: Insular, 2002.

TAVARES, Elanie. Simón Rodríguez: plantador de uma nova América. Revista Brasileira de Estudos Latinoa-Americanos, Porto Alegre, v. 3, n. 2, p. 183-192, 2013.

UNESCO. Instituto de Estadística. Compendio mundial de la educación: comparación de las estadísticas de educación en el mundo. Canadá: UIS, 2009. Disponível em: <http://www.uis.unesco.org/Library/Documents/ ged09-es.pdf>. Acesso em: 7 nov. 2013. 
VENEZUELA. Ministerio de Educación, Cultura y Deportes. Despacho del Ministro. Resolución no 179, de 15 de septiembre de 1999. Gaceta Oficial, no 36.793, Caracas, 23 sep. 1999a.

VENEZUELA. Ministerio de Educación, Cultura y Deportes. Despacho del Ministro. Resolución no 177, de 8 de septiembre de 1999. Gaceta Oficial, no 36.793, Caracas, 23 sep. 1999b.

VENEZUELA. Constitución de la República Bolivariana de Venezuela. Gaceta Oficial, Caracas, 24 mar. 2000.

VENEZUELA. Ministerio de Educación y Deportes. Escuelas Bolivarianas: avance cualitativo del proyecto. Caracas: Grabados Nacionales, 2006.

VENEZUELA. Ministerio del Poder Popular para la Educación. Diseño curricular del sistema educativo bolivariano. Caracas: Fundación Imprenta Ministerio del Poder Popular para la Cultura, 2007a.

VENEZUELA. Sistema Educativo Bolivariano. Caracas, 2007b.

VENEZUELA. Proyecto Nacional Simón Bolivar - Primer Plan Socialista (PPS): Desarrollo Económico y Social de la Nación 2007-2013. Caracas, 2007c. Disponível em: <http://www.gobiernoenlinea.ve/noticias-view/ shareFile/PPSN.pdf>. Acesso em: 15 jun. 2009.

VENEZUELA. Ministerio del Poder Popular para la Comunicación y la Información. Socialismo del Siglo XXI: La fuerza de los pequeños. Caracas: MINCI, 2007d. Disponível em: <http://www.minci.gob.ve/libros_ folletos/6/p--15/tp--28/libros_folletos.html>. Acesso em: 23 ago. 2010.

VENEZUELA. Asamblea Nacional. Ley Orgánica de Educación. Caracas, 2009.

VENEZUELA. Ministerio del Poder Popular para la Educación

Universitaria. La Revolución Bolivariana en la Educación Universitaria 19992009. Caracas: MPPEU, 2010.

ZAMORA, Frente Campesino Ezequiel; BOLÍVAR, Frente Comunal Simón. Dominación versus liberación, la necesidad de construir el socialismo bolivariano aqui y ahora. In: JORNADA BOLIVARIANA, 5., 2009, Florianópolis. Anais... Florianópolis: UFSC/IELA, 2009. Disponível em: $<$ http://www.iela.ufsc.br/cd2009/artigos/JornadasBolivarianas_dominacion_ versus_liberacion.pdf>. Acesso em: 14 dez. 2009. 


\section{Integración Latinoamericana en la Educación Bolivariana de Venezuela: concretud y formación desde el sur}

\section{Resumen}

El "espectro" de la integración de América ronda el continente, y nuestra inquietud se ha movido por el desarrollo revelador que ha adquirido la educación Bolivariana en Venezuela desde 1999 hasta 2009. Se propone a identificar y analizar la categoría de la integración latinoamericana en los documentos oficiales y en el fundamento jurídico en la educación venezolana. La integración, concebida como la cooperación, la solidaridad y la complementariedad, ha sido un instrumento importante en las luchas anti-imperialistas y anti-capitalistas, así como para el mundo multipolar deseado por el país. Compartimos la opinión de que la educación no es una esfera individual ni hegemónica delante de las relaciones sociales en las cuales está "sumergida". Así, la categoría de análisis parten de las orientaciones filosóficas del plan de estudios, en las características de las Escuelas Bolivarianas, en los objetivos y contenidos del Liceo, en la definición de Estado Docente, como una de las finalidades de la LOE/2009, y en esa dirección el interés en la búsqueda de su concreción, ya que orienta la formación del "hombre nuevo venezolano" y la construcción del socialismo en el siglo XXI.

Palabras claves: Integración regional; Venezuela; Política educativa.
Latin American integration
in the Bolivarian Education
of Venezuela: concreteness
and formation from the south

Abstract

The "spectrum" of Latin American integration rounds the continent, and our concerns were moved by the revealing unfolding that it acquired in the Bolivarian education of Venezuela from 1999 to 2009. The article proposes to identify and analyze the category of Latin American integration expressed in official documents and in the legal base in Venezuelan education. Integration, conceived as cooperation, solidarity and complementarity, has been an important tool in the anti-imperialist and anti-capitalist fights and for the multipolar world desired by the country. We share the view that education has neither individual nor hegemonic characters before the social relations that it is "dipped into". Therefore, it expresses the analytical category in the philosophical orientations of the curriculum, in the character of the Bolivarian Schools, in the objectives and content of the Lyceum, in the definition of Teaching State and as one of the OLE/2009 purposes, hence the interest in pursuing its concreteness, for it guides the formation of the "new Venezuelan man" and the construction of socialism in the XXI Century.

Keywords: Regional integration. Venezuela. Education policy. 


\section{Débora Villetti Zuck}

E-mail: debi_vz@hotmail.com

Francis Mary Guimarães Nogueira

E-mail: guimanog@terra.com.br

Enviado em: $30 / 3 / 2013$

Versáo final: $21 / 2 / 2014$

Aprovado em: 24/2/2014 